\title{
Periodontal parameters and oral hygiene in diabetic and nondiabetic adolescents in Zanjan
}

\author{
Bahareh Nazemi Salman ${ }^{1}$, Samira Basir Shabestari ${ }^{2}$, Mahsa Shaboyi Jam $^{3}$, Sarira Alizadeh Tari ${ }^{3}$, Iman Shirinbak*4 (D)
}

Received: 16 Jul 2019

Published: 26 Feb 2020

\section{Abstract}

Background: Periodontal disease and diabetes mellitus are 2 most common encountered chronic diseases. The occurrence, appearance, and severity of the periodontium tissue conditions vary during adolescence. Also, there is controversy about the relationship between diabetes mellitus and increased periodontal disease breakdown during puberty. This study aimed to assess the periodontal parameters and oral hygiene in diabetic and nondiabetic adolescents in city of Zanjan.

Methods: In this case and controls study, 140 diabetic (case) and 140 nondiabetic (control) adolescents were compared. The participants were matched by age, sex, and socioeconomic status using the group matching method. Clinical attachment loss, periodontal pocket depth, gingival index, periodontal index, and bleeding on probing were measured for the 6 Ramfjord index teeth. Data were analysed using descriptive statistics, chi-square test, $\mathrm{t}$ test, and one-way ANOVA using SPSS version 18.

Results: The mean age of the diabetic and nondiabetic group was $16.7 \pm 1.6$ and $17.1 \pm 0.30$ years, respectively. Duration of diabetes was $2.15 \pm 0.86$ years. Mean clinical attachment loss, periodontal pocket depth, gingival index, and bleeding on probing in the patient group were $7.4,1.68,12.9$, and $97.7 \%$, respectively. All these indices in diabetic adolescents were significantly greater than in nondiabetics. Only the PI was poor in both groups and no significant difference was noted in this respect between the 2 groups.

Conclusion: Both diabetic and nondiabetic adolescents had equally poor oral hygiene. Gingivitis and periodontitis indices were significantly poorer in diabetic patients.

Keywords: Diabetes Mellitus, Oral hygiene, Periodontal diseases, Health

Conflicts of Interest: None declared

Funding: Private funding

\section{*This work has been published under CC BY-NC-SA 1.0 license. \\ Copyright $\odot$ Iran University of Medical Sciences}

Cite this article as: Nazemi Salman B, Basir Shabestari S, Shaboyi Jam M, Alizadeh Tari S, Shirinbak I. Periodontal parameters and oral hygiene in diabetic and nondiabetic adolescents in Zanjan. Med J Islam Repub Iran. 2020 (26 Feb);34:12. https://doi.org/10.47176/mjiri.34.12

\section{Introduction}

Diabetes mellitus (DM) is the most common metabolic disorder and is among the most important public health dilemmas worldwide (1). There is a steady rise of DM in childhood, and the frequency of children diagnosed with

Corresponding author: Dr Iman Shirinbak,im.shirinbak@abzums.ac.ir

1. Department of Pediatric Dentistry, School of Dentistry, Zanjan University of Medical Sciences, Zanjan, Iran

2. Firoozgar Hospital, Iran University of Medical Sciences, Tehran, Iran

3. Zanjan, Iran

4. Department of Oral and Maxillofacial Surgery, School of Dentistry, Alborz University of Medical Sciences, Karaj, Iran
DM approximately doubles every decade. This disease poses some complications, especially on oral health (2).

DM causes several systemic disorders (retinopathy, neu-

$\uparrow$ What is "already known" in this topic:

The occurrence and severity of the gingival conditions is variable during adolescence. There is controversy about the relationship between diabetes mellitus and increased periodontal disease breakdown during puberty. To find the causes of health care inequality, the relationship between the periodontal parameters and oral hygiene status in diabetic and nondiabetic adolescents should be assessed.

$\rightarrow$ What this article adds:

Although both diabetic and nondiabetic adolescents had equally poor oral hygiene, periodontal parameters were significantly greater in diabetic adolescents than nondiabetics. Thus, to improve the public health, targeted oral health programs should be provided for diabetic adolescents. 
ropathy, nephropathy, cardiovascular diseases, and nontraumatic lower limb amputations) and orodental complications (dental abscesses, xerostomia, periodontal disease, and tooth loss) $(3,4)$. The number of DM patients has been increasing in many developing countries, especially among the younger people, which has a negative effect on their quality of life and increases hospitalization period with subsequent raising burden on health care costs (5). In contrast to healthy individuals, periodontal disorders occur at younger ages. Moreover, gingival involvement is usually manifested at earlier ages in diabetic teenagers (6).

Periodontal disease (PD) is the sixth main complaint of diabetic patients. Presence of chronic diseases such as PD can negatively affect DM management (7). Evidence shows a mutual relationship between metabolic control of diabetes by eliminating bacterial infection in PD and increased severity of periodontitis due to inadequate control of DM (7, $8)$. Thus, assessment of oral hygiene $(\mathrm{OH})$ status and periodontal health of diabetic patients is particularly important. Moreover, adolescents account for a large number of diabetic patients (9). While experiencing rapid biological and hormonal changes, adolescents are developing independence from parents. It is generally believed that DM is associated with development of psychological problems in adolescence (10).

During the puberty phase, there is an increase in growth hormone $(\mathrm{GH})$ production, with subsequent raise in glucose release due to enhanced gluconeogenesis and glycogenolysis processes (11). As a result of psychological crisis following hormonal changes, this group of patients need more precise supervision and hygienic screening (12).

On the other hand, inflammation in children is different from that in adults because their immunological processes are deficient as the result of incomplete development of immune cells. Therefore, conversion of T to B lymphocytes is not performed adequately. To our knowledge, B lymphocytes produce the main portion of destructive cytokines in inflammatory conditions (13). As a result, destructive processes during inflammation, which are proportionate to the amount of dental plaque, do not progress as those in adults $(14,15)$. Moreover, due to the small number of plasma cells, chronic gingivitis in children is similar to the initial stage of disease in adults, which is nondestructive and nonprogressive (13).

However, although DM does not directly cause gingivitis and PD in children, there is controversy in this regard in the literature. Evidence shows that in diabetic patients, inflammatory response of the periodontal tissue changes to a proinflammatory condition (dental plaque). Also, studies have shown that formation of dental calculus in diabetics is higher than that in nondiabetics $(1,12,14)$. However, Siudikienè et al indicated that despite standardization of samples in terms of $\mathrm{OH}$, diabetic adolescents were more susceptible to dental calculus formation than nondiabetics (16). Tonetti et al showed that the global load of PD is considerable. Pattern of population growth, alteration of risk factors, and increased tooth retention will significantly increase the socioeconomic load of periodontitis (17). Thaper et al stated that DM affects all periodontal parameters, including bleeding on probing (BOP), periodontal pocket depth (PPD), clinical attachment level (CAL), and tooth loss. However, there is no evidence supporting higher risk of dental caries and PD in diabetic adolescents (18). Negrato CA et al and Tuleutaeva $S$ et al reported that periodontal involvement among children with type 1 diabetes is inevitable $(19,20)$. Gupta et al and Ramesh et al could not find a correlation between DM and PD (21, 22). Pihlstrom and Buse indicated that there is not any vivid clinical trial that can answer all questions regarding ideal treatment for PD. It demonstrates ineffectiveness of nonsurgical periodontal therapy in reducing hyperglycemia in most patients diagnosed with type 2 diabetes (23). However, plaque accumulation and prevalence of gingivitis in diabetic adolescents and young adults were reported to be higher than in healthy individuals (24). However, Lopez et al showed that there was not any statistical difference in term of dental health status (25).

Periodontitis and diabetes are 2 most common encountered chronic diseases $(1,7)$. The occurrence, appearance, and severity of periodontal conditions is variable during adolescence (26). As a result of hormonal changes and psychological issues at the puberty phase, studies have shown contradictory relationship between blood glucose levels, periodontal condition, and oral health. In addition, the periodontium tissue is a common site for presentation of malignant and benign tumours. Some researchers reported cases such as medullary thyroid carcinoma and shwannoma which manifested in gingival mucosa of adolescent and young population. Thus, evaluation of periodontium is critical $(27,28)$. Therefore, it is crucial to make a comparison among periodontal indexes and oral health in diabetic and nondiabetic adolescents. This study was designed to assess periodontal parameters and oral hygiene in diabetic and nondiabetic adolescents in Zanjan.

\section{Methods}

In this case and controls study, 140 diabetic adolescents were randomly selected among those presenting to the Metabolic Disease Research Center in Zanjan, Iran, and constituted the patient group. The control group comprised of 140 nondiabetic adolescents randomly selected among those presenting to dental school.

Time was chosen as a randomization component. Any patient that was present in odd days of the week and met the inclusion criteria was selected as a case group until their number reached 140. Group matching method was used to adjust for age, sex, and socioeconomic effects in case and control groups. Those friend or family members that accompanied the cases were considered as controls if they met the inclusion criteria. Those individuals who completed medical and dental records and aged between 10 to 19 years and whose parents agreed to take part in the research were entered (29). The exclusion criteria were positive history of any systemic diseases such as epilepsy, Sjogren disease, dry mouth, malignancy, and immune system disorders. Moreover, patients under orthodontic or periodontal treatment, recent antibiotic therapy, those who experienced chemotherapy and radiotherapy or taking drugs with potential effect on periodontal tissue (phenytoin, cy- 
closporine, antihypertensive drugs, calcium channel blockers, and nifedipine), or those abusing tobacco or alcohol were also excluded $(1,14,20)$.

The criteria for diagnosis of DM are as follows: classic symptoms of hyperglycemia (polyuria, polydipsia, and unexplained weight loss) plus fasting glucose $\geq 126 \mathrm{mg} / \mathrm{dL}$ $(7.0 \mathrm{mmol} / \mathrm{L})$, casual glucose concentration $\geq 200 \mathrm{mg} / \mathrm{dL}$ $(11.1 \mathrm{mmol} / \mathrm{L})$, or 2-hour glucose $($ OGTT) $\geq 200 \mathrm{mg} / \mathrm{dL}$ $(11.1 \mathrm{mmol} / \mathrm{L})$, and hemoglobin A1c $(\mathrm{HbA} 1 \mathrm{c}) \geq 6.5 \%$ (48 $\mathrm{mmol} / \mathrm{mol})(14,30)$.

This study was done in accordance with the declaration of Helsinki. Also, ethical approval was obtained from the ethics committee of Zanjan University of Medical Sciences, Iran (NO: 920217). The aim and procedures were explained to all participants prior to the study. Parents of both groups also signed an informed consent. Data were collected by clinical examination, reviewing patient files, and filling out a questionnaire. The questionnaire and the examination form had 2 parts. The first part asked about demographic information, physical activity, orodental hygiene (dental flossing, tooth brushing, use of mouthwash), and dental visits. Blood glucose level and its control were also retrieved from patients' files and recorded in the questionnaire $(31,32)$. The second part included periodontal status and $\mathrm{OH}$.

The gingival index (GI) was measured according to the Silness and Loe (33). Also, BOP, CAL (34), periodontal pocket depth (PPD), and periodontal index (PI) were measured according to the O'Leary's index (35) around the 6 Rumford index teeth: (1) maxillary left central incisor, (2) first premolar, (3) maxillary right first molar, (4) mandibular left first molar, (5) mandibular right central incisor, and (6) first premolar (33-35). All patients were examined with dental explorer, mouth mirror, and (Williams and WHO) periodontal probe. Periodontitis severity was evaluated based on average CAL and attachment loss (eg, distance of CEJ and pocket depth). CAL parameter was categorized as below: $\mathrm{CAL} \leq 3 \mathrm{~mm}$ (normal), $3<\mathrm{CAL} \leq 4 \mathrm{~mm}$ (mild), $4<$ $\mathrm{CAL} \leq 5 \mathrm{~mm}$ (moderate), and CAL $>5 \mathrm{~mm}$ (severe) (31). This was done to assess the prevalence of PD $(20,36)$.
Findings were analysed by chi-square test, descriptive statistics (central dispersion indices and frequency distribution), and independent $t$ test via SPSS software (version 18, SPSS Inc., Chicago, IL, USA). P value $<0.05$ was considered significant.

\section{Results}

In this study, a total of 280 adolescents, including 140 diabetics (69 males; 71 females) and 140 nondiabetics (70 males; 70 females) were evaluated. Of the participants, 139 $(49.6 \%)$ were male and $141(50.4 \%)$ were females. Duration of diabetes was also $2.15 \pm 0.86$ years. The mean age of the diabetic and nondiabetic group was $16.7 \pm 1.06$ and $17.1 \pm 0.30$ years, respectively.

The severity of gingival inflammation (BOP), the mean PPD, and GI in diabetic adolescents were significantly higher than in nondiabetic adolescents $(p<0.001)$. On the other hand, CAL was significantly higher in diabetic adolescents than in control group $(\mathrm{p} \leq 0.001)$. However, the mean PI of the 2 groups was not significantly different $(\mathrm{p}=0.182)$ (Table 1).

The frequency of low, moderate, and severe GI, PI, CAL, and BOP was compared between the 2 groups controlling the following variables: dental flossing, tooth brushing, blood glucose control, use of mouthwash, exercise, and frequency of daily tooth brushing.The BOP was not significantly different based on the above-mentioned variables in the 2 groups ( $p>0.05)$ (Table 2).

However, significant differences were noted in CAL of diabetics based on dental flossing $(\mathrm{p}=0.014)$, frequency of tooth brushing $(\mathrm{p}=0.051)$, and blood glucose control (BGC) $(p=0.047)$. However, in nondiabetics, the CAL was not significantly different based on the above-mentioned variables.

The amount of PI was not significantly different in diabetics in terms of these variables, but it was significantly different in nondiabetics based on exercising $(p=0.043)$.

Significant differences were also noted in GI based on dental flossing $(\mathrm{p}=0.003)$, using mouthwash $(\mathrm{p}=0.025)$, and BGC $(p=0.052)$. However, in nondiabetics, the GI was not

Table 1. Comparing PPD, BOP, GI, and CAL between diabetic and nondiabetic adolescents

\begin{tabular}{|c|c|c|c|}
\hline Periodontal parameters & Diabetic adolescents & Nondiabetic adolescents & $\mathrm{P}$ value \\
\hline PPD & $1.86(0.61)^{*}$ & $1.05(0.22)$ & $<0.001^{\&}$ \\
\hline \multicolumn{4}{|c|}{ Severity of gingival inflammation (BOP) } \\
\hline Low $(0-0.24)$ & 0 & $48(35.6)$ & \multirow[t]{3}{*}{$<0.001$} \\
\hline Moderate $(0.25-0.74)$ & $3(2.3)$ & $69(51.1)$ & \\
\hline Severe $(\geq 0.75)$ & $129(97.7)$ & $18(13.3)$ & \\
\hline \multicolumn{4}{|l|}{ GI } \\
\hline Healthy $(0-0.9)$ & $42(30.2)^{\$}$ & $105(77.8)$ & \multirow[t]{4}{*}{$<0.001^{\epsilon}$} \\
\hline Low $(1-2)$ & $79(56.8)$ & $29(21.5)$ & \\
\hline Moderate $(2.1-4)$ & $17(12.2)$ & $1(0.7)$ & \\
\hline Severe $(\geq 4.1)$ & $1(0.7)$ & 0 & \\
\hline \multicolumn{4}{|l|}{ CAL } \\
\hline Healthy $(0-0.9)$ & $2(1.5)^{\$}$ & $2(1.4)$ & \multirow{4}{*}{$<0.001^{\epsilon}$} \\
\hline Low $(1-2)$ & $38(28.1)$ & $124(89.2)$ & \\
\hline Moderate $(2.1-4)$ & $93(68.9)$ & $13(9.4)$ & \\
\hline Severe $(\geq 4.1)$ & $2(1.5)$ & 0 & \\
\hline \multicolumn{4}{|l|}{ PI } \\
\hline Good & $1(0.7)$ & $3(2.14)$ & \multirow[t]{3}{*}{0.183} \\
\hline Moderate & $5(3.6)$ & $10(7.14)$ & \\
\hline Weak & $134(95.7)$ & $127(90.71)$ & \\
\hline
\end{tabular}




\begin{tabular}{|c|c|c|c|c|c|c|c|c|}
\hline \multirow[t]{2}{*}{ Oral hygiene } & \multirow{2}{*}{$\frac{\text { Sample group }}{\text { Severity }}$} & \multicolumn{3}{|c|}{ BOP in diabetic adolescents } & \multicolumn{3}{|c|}{ BOP in nondiabetic adolescents } & \multirow[t]{2}{*}{ P value } \\
\hline & & Low & Moderate & Severe & Low & Moderate & Severe & \\
\hline \multirow[t]{2}{*}{ Dental flossing } & Yes & -- & $1(0.8)$ & $34(25.8)$ & $25(18.5)$ & $37(27.4)$ & $12(8.9)$ & $0.512^{\#}$ \\
\hline & No & -- & $2(1.5)$ & $95(72)$ & $23(17)$ & $32(23.7)$ & $6(4.4)$ & \\
\hline \multirow[t]{4}{*}{ Blood glucose control } & Daily & -- & 0 & $6(4.6)$ & - & - & - & $0.821^{\&}$ \\
\hline & Weekly & -- & 0 & $13(9.9)$ & - & - & - & \\
\hline & Monthly & -- & $2(1.5)$ & $53(40.5)$ & - & - & - & \\
\hline & $\begin{array}{c}\text { Whenever I } \\
\text { Can }\end{array}$ & -- & $1(0.8)$ & $56(42.7)$ & - & - & - & \\
\hline \multirow[t]{2}{*}{ Using mouthwash } & Yes & -- & $1(0.8)$ & $19(14.4)$ & $11(8.1)$ & $15(11.1)$ & $6(4.4)$ & $0.045^{\#}$ \\
\hline & No & -- & $2(1.5)$ & $110(83.3)$ & $37(27.4)$ & $54(40)$ & $12(8.9)$ & \\
\hline \multirow[t]{2}{*}{ Exercising } & Yes & & 0 & $30(22.7)$ & $14(10.4)$ & $13(9.6)$ & $3(2.2)$ & $0.031^{\#}$ \\
\hline & No & & $3(2.3)$ & $99(75)$ & $34(25.2)$ & $56(41.5)$ & $15(11.1)$ & \\
\hline \multirow{3}{*}{$\begin{array}{l}\text { Frequency of daily } \\
\text { tooth brushing }\end{array}$} & 0 & -- & 0 & $48(36.6)$ & $8(5.9)$ & $8(5.9)$ & $4(3)$ & $0.040^{\#}$ \\
\hline & Once Daily & -- & $2(1.5)$ & $63(48.1)$ & $18(13.3)$ & $34(25.2)$ & $9(6.7)$ & \\
\hline & >Once Daily & -- & $1(0.8)$ & $17(13)$ & $22(16.3)$ & $27(20)$ & $5(3.7)$ & \\
\hline
\end{tabular}

\#: Kendalls tau test, \&: Chi_square test

significantly different based on the above-mentioned variables.

\section{Discussion}

This study was unique as it was designed to compare the different severity and type of periodontal indexes, oral hygiene approaches, and physical activity of the adolescent population $(\mathrm{N}=280)$.

Some of the limitations to be mentioned are extensive exclusion criteria, lack of patient's cooperation, incompleteness of information in records, and homogenization of sex and social levels. In this study, diabetics and nondiabetics were significantly different in terms of severity of periodontal tissue inflammation determined by BOP. Similarly, Preshaw et al reported that diabetics had higher BOP than the nondiabetics (31). Moreover, Meenawat A et al reported that this index was significantly higher in type I diabetic patients (32).

In this study, similar to research of Patinomarin et al, CAL was significantly different in diabetic and nondiabetic adolescents (36). Also, the present study was in agreement with that of Grossi et al which showed that CAL had no significant correlation with the frequency of dental visits but had a significant correlation with blood glucose control.

The present study, in line with that of Patinomarin et al (36) and Preshaw et al (31), showed that the mean PPD in diabetic adolescents was significantly higher than that in healthy individuals. Thus, it seems that diabetic adolescents are at higher risk of PD progression compared to nondiabetics. There is some evidence supporting that diabetes has an adverse effect on periodontal status and PD has an adverse effect on controlling glucose level $(19,37)$.

In a similar study, Mazhari et al reported the frequency of moderate to severe gingival inflammation in diabetic adolescents $(12.9 \%)$, which was significantly higher than that in healthy individuals $(0.7 \%$, moderate inflammation). Moreover, in agreement with the results of Mazhari et al, GI was not significantly correlated with BGC and dental visits (38). However, the value of this index in the study by Apoorva et al was much higher than that in this study (39). This difference in the prevalence of gingivitis can be due to higher severity of PD in patients who have DM for a long time compared to nondiabetics (37). However, in contrast to this study, Siudikiene et al and Apoorva et al stated that
BGC was effective in decreasing the severity of PD (16, 39). Controversy in the results of different studies may be due to difference in sample size and periodontal indices studied.

The findings of the present study, in agreement with those of Patinomarin (36) and Mazhari et al (38), showed that PI was not significantly different between diabetics and nondiabetics, while Siudikiene et al (16) demonstrated that PI in diabetics was significantly higher than that in nondiabetics. Santos showed that systemic antibiotic therapy in diabetic patients has relatively insignificant benefits in terms of decrease in mean $\mathrm{PD}$ and mean percentage of BOP (40).

In nondiabetic patients of this study, none of the periodontal parameters (GI, BOP, PI or CAL) had a significant correlation with $\mathrm{OH}$, but CAL and GI in diabetics were significantly correlated with $\mathrm{OH}$. The controversy in the results of this study can be due to very poor $\mathrm{OH}$ of adolescents in both groups. Irrespective of psychological crisis secondary to hormonal changes, the poor $\mathrm{OH}$ can be due to cultural deprivation and no access to hygienic information which may result in infrequent dental visits and not paying attention to $\mathrm{OH}(19,36)$. Moreover, lack of strong motivation for $\mathrm{OH}$ control is another possible reason for not seeking dental care by adolescents (41).

However, the role of DM in development of PD has not yet been well established (42). Type $2 \mathrm{DM}$ and poor control of glucose level have negative effects on periodontal health status (43). There are some hypotheses stating that DM increases the susceptibility to juvenile periodontitis via different mechanisms, including nonenzymatic processes producing advanced glycation end products that negatively affect the activity of proinflammatory cytokines, including IL-1 and tumor necrosis factor, and increases the expression of toll-like receptors $(42,44)$.

Frequent infections due to immunological changes in diabetics and impaired function of polymorphonuclears, impaired blood flow in capillaries, and changed response of proinflammatory proteins in the gingival tissue are among other possible mechanisms. Change in the subgingival microbial flora and emergence of anaerobic Gram-negative bacteria have also been reported in diabetic adolescents (42). The severity of DM and PD is also indirectly corre- 
lated with the factors affecting general health such as nutrition, quality of life, and $\mathrm{OH}(45)$.

Since this study has differences with previous studies in terms of number and age of patients, periodontal indices measured, study variables and ethnicity and race of patients, further studies with a larger sample size are required to assess some other indices to increase the generalizability of results to the entire population of diabetic adolescents (42).

\section{Conclusion}

All periodontal parameters (except PI) in diabetic adolescents were significantly greater than those in nondiabetics. Both diabetic and nondiabetic adolescents had equally poor oral hygiene.

In dental clinics with special focused care for patients with severe periodontitis, screening programs for diabetes should be available to identify new cases of diabetes early. This will prevent some severe complications and can benefit periodontitis therapy. Therefore, targeted oral health program should be developed for this population to promote public health.

\section{Acknowledgments}

The authors would like to thank the contribution of Metabolic Disease Research Center of Zanjan University of Medical Sciences, and all of patients who participated in this study.

\section{Conflict of Interests}

The authors declare that they have no competing interests.

\section{References}

1. Little JW, Miller C, Rhodus NL. Dental management of the medically compromised patients. $9^{\text {th }}$ ed. St. Louis: Mosby; 2017. pp. 21-5.

2. Samardžiæ M, Popoviæ N, Popoviæ-Samardžiæ M, NedoviæVukoviæ M. Rising incidence of childhood type 1 diabetes in Montenegro. Srp Arh Celok Lek. 2016;144(7-8):408-12.

3. Heidary SH, Shirazi F, Sanjari M, Salimi S, Baljani E. Evaluation of effective factors on the patients with type 2 diabetes admission to institute endocrine \& metabolism of Iran University of Medical Science. Iran J Diabet Lipid Dis. 2010;9(4):365-75.

4. Carneiro VL, Fraiz FC, Ferreira FM, Pintarelli TP, Oliveira ACB, Silva BMC. The influence of glycemic control on the oral health of children and adolescents with diabetes mellitus type 1. Endocrinol Metab. 2015;59(6):535-40

5. Ferreira Brito AMA, Veraci Oliveira QM, Salete Bessa JM. Diabetes mellitus in adolescence: experiences of adolescents and their mothers. Rev esc enferm 2009; 43(4): 760-767.

6. Novotna M, Podzimek S, Broukal Z, Lencova E, Duskova J. Periodontal diseases and dental caries in children with type 1 diabetes mellitus. Mediators Inflamm. 2015;2015:379626

7. Soori M. Periodontal Disease Severity and Systemic Diseases Prevalent in a Caribbean Catchment Area of Patients. West Indian Med J. 2007;56(2):190.

8. Chang PC, Lim LP. Interrelationships of periodontitis and diabetes: A review of the current literature. J Dent Sci. 2012;7(3):272-282.

9. Deshpande K, Jain A, Sharma RK, Prashar S, Jain R. Diabetes and periodontitis. J Indian Soc Periodontol. 2010;14(4):207-212.

10. Jaser SS. Psychological Problems in Adolescents with Diabetes. Adolesc Med State Art Rev. 2010;21(1):138-51.

11. Shin-Hye Kim SH, Park MJ. Effects of growth hormone on glucose metabolism and insulin resistance in human .Ann Pediatr Endocrinol Metab. 2017;22:145-152
12. Al-Ghutaimel H, Riba H, Al-Kahtani S, Al-Duhaimi S. Common Periodontal Diseases of Children and Adolescents. Int J Dent. 2014;8(5):674-9.

13. Chávarry NG, Vettore MV, Sansone C, Sheiham A. The relationship between diabetes mellitus and destructive periodontal disease: a metaanalysis. Oral Health Prev Dent. 2009;7(2):107-27.

14. Goldman L, Andrew I, Schafer MD. Goldman's Cecil Medicine. 25 th ed. Philadelphia: W.B Saunders; 2016.pp. 236-9.

15. Kina JR, Suzuki TYU, Kina EFU, Kina J, Kina M. Non-Inflammatory Destructive Periodontal Disease. Open Dent J. 2016; 10:50-57.

16. Siudikiene J, Maciulskiene V, Dobrovolskiene R, Nedzelskiene I. Oral hygiene in children with type I diabetes mellitus. Stomatolog. 2005;7(1):24-7.

17. Tonetti MS, Jepsen S, Jin L, Otomo-Corgel J. Impact of the global burden of periodontal diseases on health, nutrition and wellbeing of mankind: A call for global action. J Clin Priodontol. 2017;44(5):456462

18. Thaper SH, Thaper T, Priya V, Thaper R. Prevalence of Periodontitis in diabetic and non diabetic patients. Asian J Pharm Clin Res. 2016;9(1):329-331.

19. Negrato CA, Tarzia O, Jovanovic L, Chinellato LEM. Periodontal disease and diabetes mellitus. J Appl Oral Sci. 2013;21(1):1-12.

20. Tuleutaeva S, Ashirbekova Z, Manapova D, Almurat S, Kharchenko V. Periodontal disease in children with diabetes mellitus type 1. Georgian Med News. 2014;(235):25-9.

21. Ramesh A, Thomas B, Rao A. Evaluation of the association between chronic periodontitis and acute coronary syndrome: A case control study. J Indian Soc Periodontol. 2013;17(2):210-213.

22. Gupta VK, Hiremath SS, Malhotra S. Application of community periodontal index of treatment need (CPITN) in a group of insulin dependent diabetes mellitus (IDDM) patients. Int J Diabet Dev Countr. 2013;33(1):55-59.

23. Pihlstrom BL, Buse JB. Diabetes and periodontal therapy. Am Dent Asoc 2014;145(12):1208-12.

24. Hinrichs JE. In: Newman MG, Takei HH, Klokkevold P, Carranza FA. The role of dental calculus and other predisposing factors: Carranza's clinical periodontology. $12^{\text {th }}$ ed. Philadelphia: Sauders; 2015. pp. 182-203.

25. López ME, Colloca ME, Páez RG, Schallmach JN, Koss MA, Chervonagura A. Salivary characteristics of diabetic children. Braz Dent J. 2003;14(1):26-31

26. Laala E, Cheng B, Lal SH, Tucker S, Greenberg E, Goland R, et al. Periodontal Changes in Children and Adolescents with Diabetes. Diabet Care. 2006;29:295-299.

27. Basir Shabestari S, Shirinbak I, Agha-Hosseini F. Maxillary Metastasis of a Medullary Thyroid Carcinoma in a 21-year-old Woman 7 Years After Thyroidectomy. J Oral Maxillofac Surg. 2012;70(6): 1495-9.

28. Basir Shabestari S, Shirinbak I, Saghafi-khadem S, Eshghyar N. Schwannoma in the Posterior Hard Palate and Anterior Mandibular Gingiva: a report of two cases. J Kerman Uni Med Sci. 2018;25(4):375381.

29. Sheehan P, Sweeny K, Rasmussen B, Wils A, Friedman HS, Mahon $\mathrm{J}$,et al. Our future: a Lancet commission on adolescent health and wellbeing. Lancet. 2016; 390:10104.

30. American Diabetes Association. Classification and Diagnosis of Diabetes: Standards of Medical Care in Diabetes-2018. Diabetes Care. 2018;41(Supplement 1):S13-S27.

31. Preshaw PM, Alba AL,Herrera D, Jepsen S, Konstantinidis A, Makrilakis K ,et al. Periodontitis and diabetes: a two-way relationship. Diabetolog. 2012;55(1):21-31.

32. Meenawat A, Punn K, Srivastava V, Meenawat AS, Dolas RS, Govila V. Periodontal disease and type I diabetes mellitus: Associations with glycemic control and complications. J Indian Soc Periodontol. 2013;17(5):597-600

33. Newman M, Takei H, Klokkevold P, Carranza F. Newman and Carranza's Clinical Periodontology. 2018. 13th ed. USA: Elsevier. p.20814

34. Pihlstrom BL. Measurement of attachment level in clinical trials: probing methods. J Periodontol. 1992;63(12 Suppl):1072-7.

35. Loe H. The Gingival Index, the Plaque Index and the Retention Index Systems. J Periodontol. 1967;38(6):610-6.

36. Patino-Marin N, Loyola-Rodriguez JP, Medina Solis CE, PontigoLoyola AP, Reyes-Macias JF, Ortega-Rosado JC, et al. Caries, periodontal disease and tooth loss in patients with diabetes mellitus type 1 and 2. Acta Odontal Latino Am. 2008;21(2):127-133. 
37. Hemalatha VT, Manigandan T, Sarumathi T, Aarthi Nisha V, Amudhan A. Dental Considerations in Pregnancy-A Critical Review on the Oral Care. J Clin Diagn Res. 2013;7(5):948-953.

38. Mazhari F, Khordi Mood M, Esmaeili H, Tootooni H. Prevalence of periodontal diseases and oral health status, in children with type I diabetes in Khorasan, Iran in 2002. J Islam Dent Assoc. 2007;19(2):29-34. (Persian)

39. Apoorva SM, Sridhar N, Suchetha A. Prevalence and severity of periodontal disease in type 2 diabetes mellitus (non-insulin-dependent diabetes mellitus) patients in Bangalore city: An epidemiological study. J Indian Soc Periodontol. 2013;17(1):25-9.

40. Santos CM, Lira-Junior R, Fischer RG, Santos AP, Oliveira BH. Systemic Antibiotics in Periodontal Treatment of Diabetic Patients: A Systematic Review. PLoS One 2015; 10(12): e0145262.

41. Shirinbak I, Basir Shabestari S, Mokhtari H. Assessment of Dental Treatment Needs in Chemically Veterans in Zanjan, Iran. J Mil Med. 2018;19(5):468-475

42. Abdul-wahab GA, Ahmed MA. Assessment of some salivary enzymes levels in type 2 diabetic patients with chronic periodontitis (Clinical and biochemical study). Oral Maxillofac Surg Periodont. 2015;27(1):143-9.

43. Schackert HK, Agha-Hosseini F, Gorgens H, Jatzwauk M, von Kannen S, Noack B, et al. Complete homozygous deletion of CTSC in an Iranian family with Papillon-Lefevre syndrome. Int $\mathrm{J}$ Dermatol. 2014;53(7):885-7.

44. Kim EK, Lee SG, Choi YH, Won KC, Moon JS. Association between diabetes-related factors and clinical periodontal parameters in type 2 diabetes mellitus. BMC Oral Health. 2013;13(2): 64-9.

45. Teeuw WJ, Kosho MXF, Poland DCW, Gerdes VEA, Loos BG. Periodontitis as a possible early sign of diabetes mellitus. BMJ Open Diabet Res Care. 2017;5:e000326. 